\title{
Komparasi Algoritma C4.5, K-NN Dan Naïve Bayes Dalam Penerimaan Karyawan Menggunakan PSO Pada PT. XYZ
}

\author{
Taufik Asra \\ Universitas BIna Sarana Informatika \\ taufik.tas@bsi.ac.id
}

\begin{abstract}
Recruiting employees with the best quality of one of the HRD assignments to help advance the company. Employees with the best quality are expected to give a high contribution to the company later. To get the company's best employees apply a strict employee acceptance selection. The problem arises when the employee who passed the selection turns resigned when his contract period has not been fulfilled, even some disappear during the training process. This results in a high turnover in the company. The sample data used is 111 data, derived from employee data that lasts for more than 12 months, list of employees resign under 12 months and prospective employees who are rejected. After the cleansing process in the can 80 data with the details 32 received and 48 rejected. With C 4.5 algorithm optimized using PSO evaluated with confusion matrix resulted in a accuracy rate of $86.25 \%$, precision $80.83 \%$ and a $68.33 \%$ recall and a graph of AUC 0530. With the algorithm of K-NN optimized using PSO evaluated with confusion matrix to make accuracy of $82.50 \%$, precision $84.33 \%$, and $75.00 \%$ recall and graph value AUC 0.796. With the algorithm of Naîve Bayes optimized PSO that evaluated with confusion matrix to optimize the accuracy level of $91.25 \%$, precision 88.50 , $\%$ and recall of $94.17 \%$ and the graph value of AUC 0.903 .
\end{abstract}

Keywords: employee acceptance, C4.5, K-NN, Naïve Bayes, PSO

\begin{abstract}
Abstrak: Merekrut karyawan-karyawan dengan kualitas terbaik salah satu tugas HRD untuk membantu memajukan perusahaan. Karyawan dengan kualitas terbaik tersebut diharapkan memberikan kontribusi yang tinggi terhadap perusahaan nantinya. Untuk mendapatkan karyawan terbaik perusahaan menerapkan seleksi penerimaan karyawan yang ketat. Masalah muncul ketika karyawan yang lulus seleksi ternyata mengundurkan diri ketika masa kontraknya belum terpenuhi, bahkan ada yang menghilang pada saat proses training. Hal itu mengakibatkan tingginya turnover pada perusahaan. Sampel data yang digunakan ada 111 data, diambil dari data karyawan yang bertahan lebih dari 12 bulan, daftar karyawan resign dibawah 12 bulan dan calon karyawan yang ditolak. Setelah proses cleansing di dapat 80 data dengan rincian 32 diterima dan 48 ditolak. Dengan algoritma C4.5 dioptimasi menggunakan PSO yang dievaluasi dengan confusion matrix menghasilkan tingkat accuracy $86.25 \%$, precision $80.83 \%$ dan recall $68.33 \%$ serta grafik AUC 0.530 . Dengan algoritma K-NN dioptimasi menggunakan PSO yang dievaluasi dengan confusion matrix menghasikan tingkat accuracy $82,50 \%$, precision $84,33 \%$ dan recall 75,00\% serta nilai grafik AUC 0,796. Dengan algoritma Naïve Bayes dioptimasi PSO yang dievaluasi dengan confusion matrix menghasikan tingkat accuracy $91,25 \%$, precision $88,50, \%$ dan recall $94,17 \%$ serta nilai grafik AUC 0,903 .
\end{abstract}

Kata kunci: Penerimaan Karyawan, C4.5, K-NN, Naïve Bayes,PSO

(C) $(9)$ This is an open access article distributed under the Creative Commons Attribution License, which permits unrestricted use, distribution, and reproduction in any medium, provided the original work is properly cited. (O2019 by author and IJSE-Indonesian Journal on Software Engineering.

\section{A. PENDAHULUAN}

Salah satu bentuk dukungan dari divisi HRD untuk membantu memajukan perusahaan adalah dengan merekrut karyawan-karyawan dengan kualitas terbaik. Dimana karyawan dengan kualitas terbaik tersebut diharapkan memberikan kontribusi yang tinggi terhadap perusahaan nantinya. 
Dalam Penelitian yang dikembangkan (Winarso \& Arribe, 2017) mengungkapkan berdasarkan hasil penelitian yang dilakukan terhadap pengembangan sistem seleksi pegawai dan dosen UMRI berbasis E-Rekrutmen menggunakan metode K-NN, maka dapat diambil kesimpulan bahwa metode KNN mampu menyeleksi calon karyawan dan dosen pada tahap seleksi administrasi dengan cara menghitung tingkat kemiripan antara persyaratan dengan data pelamar.

Sedangkan dalam Penelitian (Asistyasari \& Baidawi, 2017) Model decision tree menggunakan algoritma c4.5 yang dievaluasi dengan confusion matrix menghasikan angka akurasi $71,54 \%+-9,13 \%$, precision $80,47 \%+/-8,16$ dan recall $83,78 \%+/-9,29 \%$ serta dengan angka curva ROC 0,721 dan dapat memberikan rekomendasi kepada PT Prismas Jamintara Jakarta dalam menentukan calon pegawai sesuai dengan kriteria yang dibutuhkan oleh klien.

PT. XYZ adalah salah satu perusahaan jasa service center handphone di Indonesia. Dengan kelangsungan jalannya usaha yang bergantung pada kepuasan pelanggan, maka perusahaan tersebut berupaya semaksimal mungkin untuk memberikan pelayanan terbaik melalui karyawan terbaiknya. Maka untuk mendapatkan karyawan terbaik tersebut perusahaan menerapkan seleksi karyawan yang ketat.

Namun walaupun sudah menerapkan seleksi karyawan yang ketat dengan harapan mendapatkan karyawan yang terbaik, ternyata permasalahan yang dihadapi PT. XYZ justru muncul ketika karyawan yang sudah lulus seleksi ternyata mengundurkan diri ketika masa kontraknya belum terpenuhi, bahkan terdapat karyawan yang menghilang pada saat proses training. Hal itu tentunya mengakibatkan tingginya turnover pada perusahaan tersebut, tercatat hampir setiap bulannya terdapat rata-rata lima karyawan keluar dan masuk pada divisi retail di satu area.

Hal itu tentunya tidak hanya membuat divisi HRD saja yang kesulitan karena harus kembali mengulangi proses pencarian kandidat baru, namun juga divisi yang membutuhkan menjadi terganggu karena kuota SDM nya belum terpenuhi. Karena pada prosesnya, setiap karyawan yang sudah lulus seleksi wajib dibekali dengan pelatihan-pelatihan yang besifat teoritis maupun teknis dengan waktu kurang lebih 2 (dua) minggu. Sehingga apabila terdapat karyawan yang mengundurkan diri pada proses training maupun masa percobaan, maka membutuhkan waktu yang cukup lama.

Dengan hanya memperhatikan kriteria-kriteria seperti yang disebutkan (Winarso \& Arribe, 2017) dan (Asistyasari \& Baidawi, 2017) tentunya tidak dapt menyelesaikan permasalahan tersebut karena tidak menyentuh permasalahan turn over tersebut, karena kebanyakan kriteria lebih kearah kemampuan dari calon karyawan bukan kriteria bahwa karyawan tersebut nantinya akan bertahan lama atau tidak.

Pendekatan yang dilakukan oleh (Kurniawan, Purwana ES., \& Widiyastuti, 2017) yang meneliti tentang turnover suatu perusahaan mengatakan bahwa nilai turnover intention dipengaruhi oleh variable job insecurity dan kepuasan kerja sebesar $55,4 \%$ dan sisanya $44,6 \%$ dipengaruhi oleh variable lain yang tidak diteliti. Dengan pendekatan ini perusahaan tentunyaharus meningkatkan jobs insecurity dan juga kepuasan kerja terhadap karyawannya. Namun hal itu bersifat subyektif karena standar jobs insecurity dan juga kepuasan kerja setiap karyawan tentunya berbeda-beda.

\section{B. TINJAUAN PUSTAKA}

\section{Algoritma $\mathrm{C} 4.5$}

Algoritma C4.5 merupakan salah satu algoritma yang digunakan dalam klasifikasi dan bersifat prediktif yang memiliki banyak kelebihan. Kelebihan ini misalnya dapat mengolah data numerik dan diskret, dapat menangani nilai atribut yang hilang satu yang tercepat dibandingkan dengan algoritma lain. Ide dasar dari algoritma ini adalah pembuatan pohon keputusan berdasarkan pemilihan atribut yang memiliki prioritas tertinggi atau dapat memiliki gain tertinggi berdasarkan nilai entrophy atribut tersebut sebagai poros atribut (Sudibyo, Asra, \& Rifai, 2018). 
Kemudian secara rekursif cabang-cabang pohon diperluas sehingga seluruh pohon terbentuk. Entropy adalah jumlah data yang tidak relevan terhadap informasi dari suatu kumpulan data. Gain adalah informasi yang didapatkan dari perubahan entropy pada suatu kumpulan data, baik melalui observasi atau bisa juga disimpulkan dengan cara melakukan partisipasi terhadap suatu set data (Sudibyo et al., 2018).

Menurut (Sudibyo et al., 2018) terdapat empat langkah dalam proses pembuatan pohon keputusan pada algoritma C4.5, yaitu:

1. Memilih atribut sebagai akar.

2. Membuat cabang untuk masing-masing nilai.

3. Membagi setiap kasus dalam cabang.

4. Mengulangi proses dalam setiap cabang sehingga semua kasus dalam cabang memiliki kelas yang sama.

Menurut (Sudibyo et al., 2018) data yang dimiliki harus disusun menjadi sebuah tabel berdasarkan kasus dan jumlah responden sebelum dilakukan perhitungan untuk mencari nilai entropy dan gain. Rumus perhitungan entropy yang digunakan untuk menentukan seberapa informatif atribut tersebut.

$$
\begin{aligned}
& \text { Entropy }(S)=\sum_{i=0}^{n}-p i * \log ^{2} p i \text {. } \\
& \text { Keterangan : } S \text { : Himpunan kasus } \\
& \mathrm{n} \text { : Jumlah partisi } \mathrm{S} \\
& \text { pi : Jumlah kasus pada partisi ke-i }
\end{aligned}
$$

Rumus yang digunakan dalam perhitungan gain setelah melakukan perhitungan entropy.

$$
\begin{gathered}
\operatorname{Gain}(S, A)=\operatorname{Entropy}(S)=\sum_{i=1}^{n} \frac{|S i|}{|S|} * \operatorname{Entropy}(S i) \\
\text { Keterangan : } \mathrm{S}: \\
\mathrm{n}: \text { Himpunan kasus } \\
|\mathrm{Si}|: \text { Jumlah partisi atribut } \mathrm{A} \\
|\mathrm{S}|: \text { Jumlah kasus pada partisi ke }-\mathrm{i}
\end{gathered}
$$

\section{2. $\mathrm{K}-\mathrm{NN}$}

Algoritma K-Nearest Neighbor (K-NN) adalah sebuah metode untuk melakukan klasifikasi terhadap objek berdasarkan data pembelajaran yang jaraknya paling dekat dengan objek tersebut. K-NN termasuk algoritma supervised learning dimana hasil dari query instance yang baru diklasifikan berdasarkan mayoritas dari kategori pada K-NN. Kelas yang paling banyak munculah yang akan menjadi hasil klasifikasi. Klasifikasi menggunakan voting terbanyak diantara klasifikasi dari k obyek. Algoritma K-Nearest Neighbor (K-NN) menggunakan klasifikasi ketetanggaan sebagai nilai prediksi dari query instance yang baru (Fauziah, Sulistyowati, \& Asra, 2019).

$p\left(x, c_{m}\right)=\sum_{l=1}^{m} \operatorname{SIM}\left(X, d_{j}\right) \in c_{m}$

Keterangan:

$\mathrm{P}(\mathrm{x}, \mathrm{cm}) \quad$ : probabilitas dokumen $\mathrm{X}$ menjadi anggota kategori $\mathrm{cm}$

$\operatorname{sim}(\mathrm{X}, \mathrm{dj}) \in \mathrm{cm}$ : kemiripan antara dokumen $X$ dengan dokumen latih dj yang merupakan anggota dari kategori $\mathrm{cm}$

m : jumlah $\operatorname{sim}(\mathrm{x}, \mathrm{dj})$ yang termasuk dalam kategori $\mathrm{cm}$

\section{Naïve Bayes}

Naïve Bayes merupakan metode dalam teknik klasifikasi dan termasuk dalam klasifikasi statistic yang dapat memprediksi probabilitas keanggotaan class. Naïve Bayes mengasumsikan bahwa nilai atribut pada sebuah class adalah independent terhadap nilai pada atribut yang lain (Adi, 2018).

\section{Particle Swarm Optimization}

Particle Swarm Optimization (PSO) adalah metode pencarian penduduk, yang berasal dari penelitian untuk pergerakan organisme dari kelompok burung atau ikan, seperti algoritma 
genetika, Particle Swarm Optimization (PSO) melakukan pencarian menggunakan populasi (swarm) dari individu (partikel) yang diperbaharui dari iterasi untuk iterasi (Musyaffa \& Rifai, 2018).

\section{METODE PENELITIAN}

Dalam penelitian ini menggunakan model CRISP-DM (Cross-Industry Standart Process for Data Mining), yang terdiri dari 6 tahapan yaitu:

\section{Business Understanding Phase (Fase Pemahaman Bisnis)}

Jalannya usaha PT. XYZ sebagai salah satu perusahaan jasa service center produk handphone di Indonesia sangat tergantung pada kepuasan pelanggan. Dengan maksud mempersiapkan karyawan terbaiknya semenjak proses rekrutmen, ternyata menghadapi masalah dengan beberapa karyawan yang keluar pada saat kontrak belum habis bahkan beberapa karyawan menghilang pada saat proses training. Oleh sebab itu dibutuhkan metode untuk mengklasifikasi dalam mengklasifikasi calon karyawan agar tidak membuat turnover semakin tinggi.

\section{Data Understanding Phase (Fase Pemahaman Data)}

Untuk pemilihan data diambil dari data karyawan yang bertahan lebih dari 12 bulan, daftar karyawan resign yang dibawah 12 bulan dan calon karyawan yang di tolak. Atribut-atribut yang diambil berasal dari data biodata pribadi karyawan, data penilaian saat interview dan test IQ, adapun atribut-atribut menjadi terlihat pada table 1 :

Tabel 1. Atribut

\begin{tabular}{|l|l|l|}
\hline No & Atribut & \multicolumn{1}{c|}{ Nilai } \\
\hline 1 & Usia & Lakd 40 tahun \\
\hline 2 & Jenis Kelamin & Lajang, Menikah, Janda/Duda \\
\hline 3 & Status Pernikahan & Tidak ada, Satu, Dua, Tiga \\
\hline 4 & Jumlah Anak & SMK/Sederajat, D3, S1, S2 \\
\hline 5 & Pendidikan Terakhir & Tidak ada, Mendukung \\
\hline 6 & Pendidikan Non Formal & Kurang, Cukup \\
\hline 7 & Bahasa Asing & Kurang, Cukup \\
\hline 8 & Penguasaan Komputer & Tidak Ada, Ada \\
\hline 9 & Keahlian Khusus & 0 sd 21 Tahun \\
\hline 10 & Pengalaman Bekerja (Tahun) & 0 sd 6 Perusahaan \\
\hline 11 & Jumlah Perusahaan & Dibawah, Diatas \\
\hline 12 & Gaji Terakhir & Ada, Tidak Ada \\
\hline 13 & Organisasi & Segera, 1 Bulan \\
\hline 14 & Mulai Bekerja & Ada, Tidak Ada \\
\hline 15 & Kenalan di Perusahaan & A,B,C \\
\hline 16 & Penilaian Umum & A,B,C \\
\hline 17 & Penilaian Standar & A,B,C \\
\hline 18 & Penilaian Spesifik & A,B,C \\
\hline 19 & Test IQ & Ditolak, Mundur, Bertahan \\
\hline 20 & Label & \\
\hline
\end{tabular}

Sumber: (Asra, 2019)

\section{Data Preparation Phase (Fase Pengolahan Data)}

Kemudian dilakukan pembentukan label diterima dan ditolak. Label diterima diambil dari 
data karyawan yang bertahan lebih dari 12 bulan sedangkan label ditolak diambil dari karyawan yang mundur dibawah 12 bulan serta karyawan yang tidak lulus seleksi.

Tabel 2. Jumlah Data Per Label

\begin{tabular}{|l|c|}
\hline Label & Jumlah \\
\hline Diterima & 45 \\
\hline Ditolak & 66 \\
\hline Jumlah data & 111 \\
\hline
\end{tabular}

Sumber: (Asra, 2019)

Selanjutnya dilakukan proses cleaning terhadap data-data yang tidak memiliki nilai pada atribut yang dipakai. Sehingga didapat jumlah data yang dapat digunakan dalam penelitian ini adalah sebanyak 80 data dengan rincian 48 data ditolak dan 32 data diterima.

Tabel 3. Jumlah Data Setelah Proses Cleaning

\begin{tabular}{|l|c|}
\hline Label & Jumlah \\
\hline Diterima & 32 \\
\hline Ditolak & 48 \\
\hline Jumlah data & 80 \\
\hline
\end{tabular}

Sumber: (Asra, 2019)

Selanjutnya dilakukan pengelompokan pada nilai-nilai atribut, untuk nilai atribut yang bernilai nominal dapat langsung digunakan pada penelitian ini seperti jenis kelamin dengan nilai laki-laki dan perempuan. Namun untuk nilai atribut yang bernilai numerik seperti usia, perlu dilakukan pengelompokan.

Tabel 4. Atribut dan Nilai Kategori

\begin{tabular}{|l|c|c|}
\hline \multicolumn{1}{|c|}{ Atribut } & Nilai Awal & \multicolumn{1}{l|}{ Nilai } \\
\hline Usia & $<28$ & A \\
\hline & $<35$ & B \\
\hline & $\geq 35$ & C \\
\hline & & \\
\hline Jenis Kelamin & L & L \\
\hline & P & P \\
\hline & & A \\
\hline Penilaian Standar & A & B \\
\hline & B & C \\
\hline & C & A \\
\hline & & B \\
\hline Penilaian Spesifik & A & C \\
\hline & B & \\
\hline & C & A \\
\hline & & B \\
\hline Test IQ & A & \\
\hline & B & C \\
\hline & C & Diterima \\
\hline & Diterima & \\
\hline Label & Ditolak & Ditolak \\
\hline & & \\
\hline
\end{tabular}

Sumber: (Asra, 2019) 
IJSE - Indonesian Journal on Software Engineering, Vol.5, No. 2, Desember 2019, 71-79 pISSN: 2461-0690 | elSSN: 2714-9935

\section{Modeling Phase (Fase Pemodelan)}

Tahap ini juga disebut tahap learning karena pada tahap ini data training diklasifikasikan oleh model dan kemudian menghasilkan keputusan. Pada penelitian ini, pembuatan model menggunakan algoritma C4.5, K-NN dan Naïve Bayes yang dioptimasi menggunakan PSO seperti yang tampak pada gambar 1 .

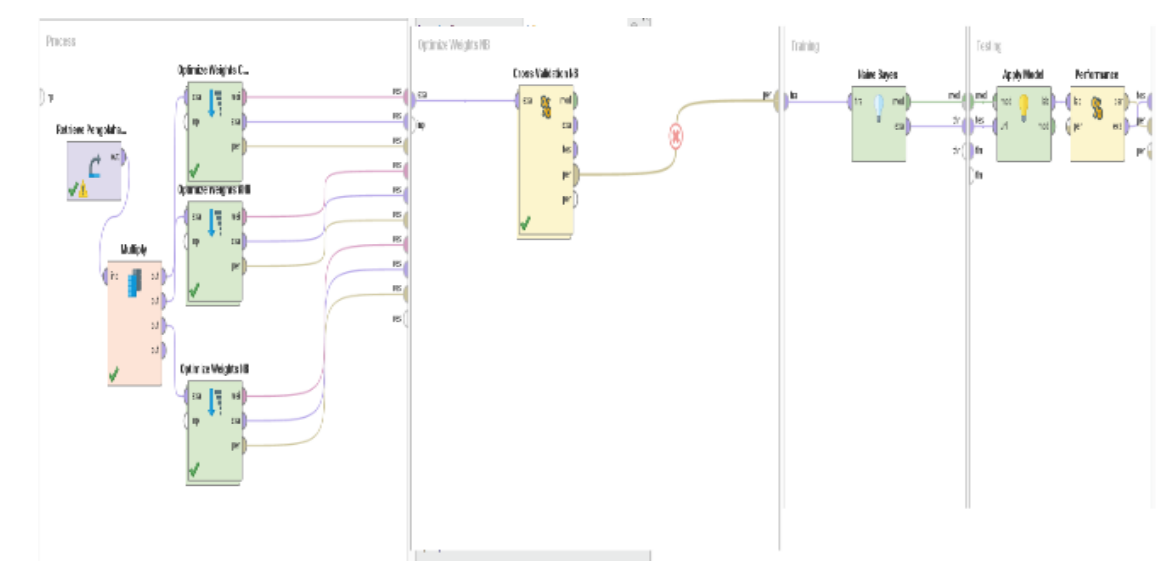

Sumber: (Asra, 2019)

Gambar 1. Modeling Pada Rapid Miner

\section{Evaluation Phase (Fase Evaluasi)}

Pada tahap ini dilakukan pengujian model untuk mendapatkan informasi model yang akurat. Dalam hal ini menggunakan confusion matrix.

\section{Deployment Phase (Fase Penyebaran)}

Setelah pembentukan model dan dilakukan analisa dan pengukuran pada tahap sebelumnya, selanjutnya pada tahap ini akan menerapkan hasil penelitian kedalam sebuah aplikasi.

\section{HASIL DAN PEMBAHASAN}

Pada penelitian ini menggunakan aplikasi Rapid Miner untuk melakukan perhitungan dan hasilnya dievaluasi menggunakan confusion matrix. Dan berikut hasil confusion matrix perhitungan menggunakan algoritma C4.5 tanpa PSO.

accuracy: 80.00\% +1-11.46\% (mikro: 80.00\%)

\begin{tabular}{|l|l|l|l|}
\hline & true Ditolak & true Diterima & class precision \\
\hline pred. Ditolak & 39 & 7 & $84.78 \%$ \\
\hline pred. Diterima & 9 & 25 & $73.53 \%$ \\
\hline class recall & $81.25 \%$ & $78.12 \%$ & \\
\hline
\end{tabular}

Sumber: (Asra, 2019)

Gambar 2. Confusion Matrix Algoritma C4.5 tanpa PSO 
Dan berikut hasil confusion matrix perhitungan menggunakan algoritma C4.5 menggunakan PSO.

\begin{tabular}{|c|c|c|c|}
\hline & true Ditolak & true Diterima & class precision \\
\hline pred. Ditolak & 44 & 7 & $86.27 \%$ \\
\hline pred. Diterima & 4 & 25 & $86.21 \%$ \\
\hline class recall & $91.67 \%$ & $78.12 \%$ & \\
\hline
\end{tabular}

Sumber: (Asra, 2019)

Gambar 3. Confusion Matrix Algoritma C4.5 menggunakan PSO

Dan nilai AUC yang dihasilkan adalah 0.530 sepertiyang tampak pada gambar 4 .

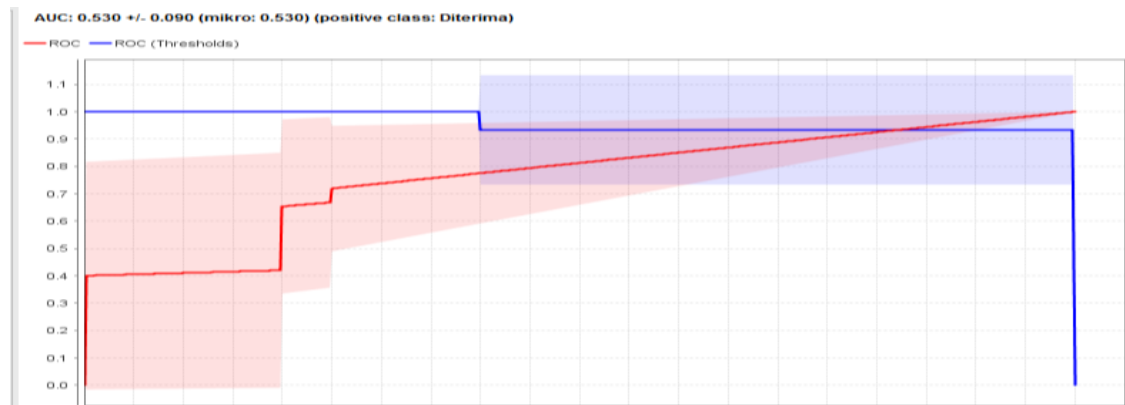

Sumber: (Asra, 2019)

Gambar 4. AUC C4.5 menggunakan PSO

Dan berikut hasil confusion matrix perhitungan menggunakan algoritma Naïve Bayes menggunakan PSO.

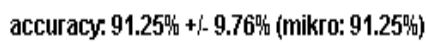

\begin{tabular}{|l|l|l|l|}
\hline & true Ditolak & true Diterima & class precision \\
\hline pred. Ditolak & 43 & 2 & $95.56 \%$ \\
\hline pred. Diterima & 5 & 30 & $85.71 \%$ \\
\hline class recall & $89.58 \%$ & $93.75 \%$ & \\
\hline
\end{tabular}

Sumber: (Asra, 2019)

Gambar 5. Confusion Matrix Algoritma Naïve Bayes menggunakan PSO

Dengan nilai UAC yang dihasilkan adalah 0.903 seperti tampak pada gambar 6 .

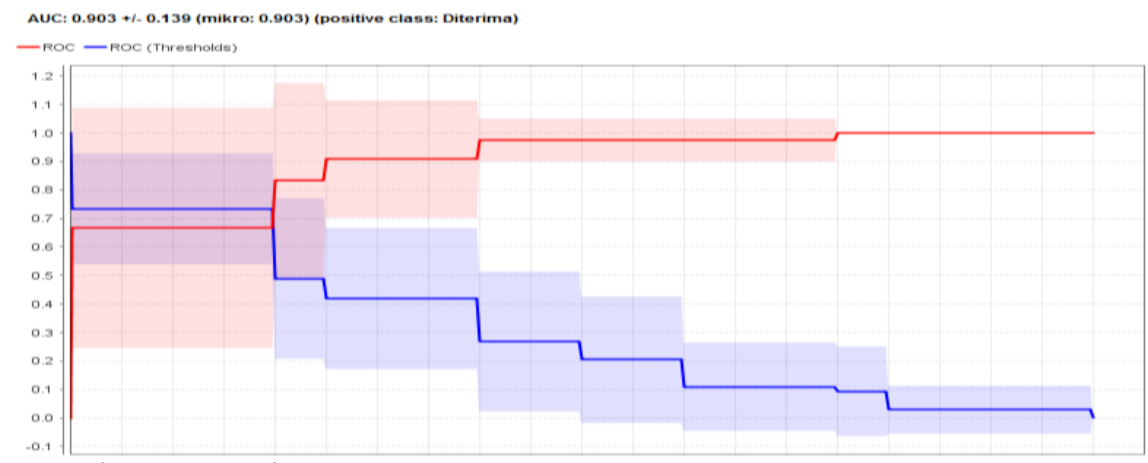

Sumber: (Asra, 2019)

Gambar 6. AUC Algoritma Naïve Bayes menggunakan PSO 
IJSE - Indonesian Journal on Software Engineering, Vol.5, No. 2, Desember 2019, 71-79 pISSN: 2461-0690 | elSSN: 2714-9935 PSO.

Dan berikut hasil confusion matrix perhitungan algoritma K-NN pada K-3 menggunakan accuracy: 82.50\% +1-11.46\% (mikro: 82.50\%)

\begin{tabular}{|l|l|l|l|}
\hline & true Ditolak & true Diterima & class precision \\
\hline pred. Ditolak & 43 & 9 & $82.69 \%$ \\
\hline pred. Diterima & 5 & 23 & $82.14 \%$ \\
\hline class recall & $89.58 \%$ & $71.88 \%$ & \\
\hline
\end{tabular}

Sumber: (Asra, 2019)

Gambar 7. Confusion Matrix Algoritma K-NN menggunakan PSO

Dan nilai UAC yang didapatkan adalah 0.796 seperti yang tampak pada gambar 8 .

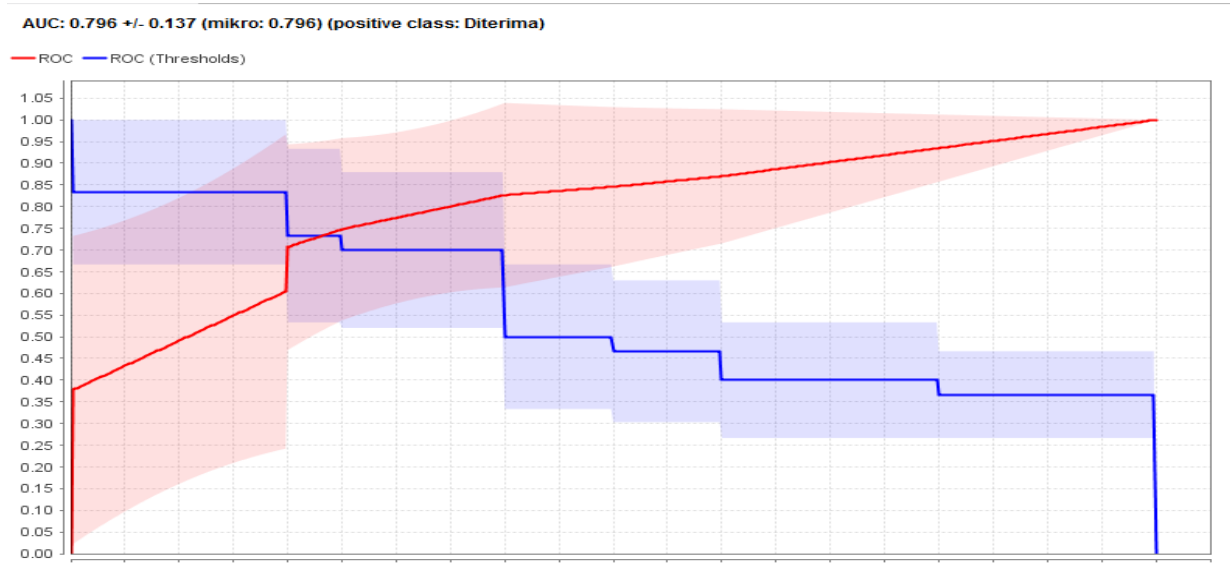

Sumber: (Asra, 2019)

Gambar 8. AUC Algoritma K-NN menggunaka PSO

\section{E. KESIMPULAN}

Berdasarkan hasil perhitungan klasifikasi dengan berbagai model yang dioptimasi menggunakan PSO menghasilkan hasil sebagai berikut:

1. Dengan algoritma C4.5 dioptimasi menggunakan PSO yang dievaluasi dengan confusion matrix menghasilkan tingkat accuracy $86.25 \%$, precision $80.83 \%$ dan recall $68.33 \%$ serta grafik AUC 0.530 .

2. Dengan algoritma K-NN dioptimasi menggunakan PSO yang dievaluasi dengan confusion matrix menghasikan tingkat accuracy $82,50 \%$, precision $84,33 \%$ dan recall $75,00 \%$ serta nilai grafik AUC 0,796.

3. Dengan algoritma Naïve Bayes dioptimasi PSO yang dievaluasi dengan confusion matrix menghasikan tingkat accuracy $91,25 \%$, precision $88,50, \%$ dan recall $94,17 \%$ serta nilai grafik AUC 0,903.

Maka dapat disimpulkan algoritma terbaik yang dapat digunkan dalam klasifikasi penerimaan karyawan adalah algoritma Naïve Bayes dioptimasi PSO yang dievaluasi dengan confusion matrix menghasikan tingkat accuracy $91,25 \%$, precision $88,50, \%$ dan recall $94,17 \%$ serta nilai grafik AUC 0,903. 


\section{REFERENSI}

Adi, S. (2018). PREDIKSI DALAM PENJURUSAN SISWA BARU TINGKAT SMA MENGGUNAKAN ALGORITMA NAÏVE BAYES CLASSIFIER. 2(2), 45-51.

Asistyasari, A., \& Baidawi, T. (2017). Analisis Penerimaan Karyawan Posisi Field Collector Menggunakan Algoritma C4.5 Pada Pt. Prismas Jamintara Jakarta. Jurnal IImu Pengetahuan Dan Teknologi Komputer, 2(2), 1-6. Retrieved from http://ejournal.nusamandiri.ac.id/ejurnal/index.php/jitk/article/view/223/199

Asra, T. (2019). Laporan Akhir Penelitian Mandiri - Komparasi Algoritma C4.5, K-NN Dan Naïve Bayes Dalam Penerimaan Karyawan Menggunakan PSO Pada PT. XYZ. Jakarta.

Fauziah, S., Sulistyowati, D. N., \& Asra, T. (2019). Optimasi Algoritma Vector Space Model Dengan Algoritma K-Nearest Neighbour Pada Pencarian Judul Artikel Jurnal. Jurnal Pilar Nusa Mandiri, 15(1), 21-26. https://doi.org/10.33480/pilar.v15i1.27

Kurniawan, D., Purwana ES., D., \& Widiyastuti, U. (2017). JOB INSECURITY, KEPUASAN KERJA DAN TURNOVER INTENTION: STUDI PADA KARYAWAN PT " $X$ ” DI JAKARTA. Jurnal Pendidikan Ekonomi Dan Bisnis (JPEB), 4(1), 92. https://doi.org/10.21009/JPEB.004.1.5

Musyaffa, N., \& Rifai, B. (2018). Model Support Vector Machine Berbasis Particle Swarm Optimization Untuk Prediksi Penyakit Liver. JITK (Jurnal IImu Pengetahuan Dan Teknologi Komputer), 3(2), 189-194. Retrieved from http://ejournal.nusamandiri.ac.id/ejurnal/index.php/jitk/article/view/593

Sudibyo, A., Asra, T., \& Rifai, B. (2018). Klasifikasi Seleksi Atribut Pada Serangan Spam. Jurnal PILAR Nusa Mandiri, 14(2), 145-150. https://doi.org/https://doi.org/10.33480/pilar.v14i2.31

Winarso, D., \& Arribe, E. (2017). Seleksi Pegawai dan Dosen UMRI Berbasis E-Recruitment. Jurnal Teknologi Informasi \& Komunikasi Digital Zone, 8(2), 71-80. https://doi.org/https://doi.org/10.31849/digitalzone.v8i2.631 